\title{
Finite Element Analysis of Chemical Reaction and Radiation Effects on Isothermal Vertical Oscillating Plate with Variable Mass Diffusion
}

\author{
S. Sivaiah, ${ }^{1}$ G. Murali, ${ }^{1}$ and M. C. K. Reddy ${ }^{2}$ \\ ${ }^{1}$ Department of Mathematics, GITAM University, Hyderabad 502 329, India \\ ${ }^{2}$ Department of Mathematics, Osmania University, Hyderabad 500 007, India \\ Correspondence should be addressed to G. Murali, muraligundagani@gmail.com
}

Received 15 May 2012; Accepted 1 August 2012

Academic Editors: K. Ammari and W.-H. Steeb

Copyright $@ 2012$ S. Sivaiah et al. This is an open access article distributed under the Creative Commons Attribution License, which permits unrestricted use, distribution, and reproduction in any medium, provided the original work is properly cited.

\begin{abstract}
The objective of this paper is to investigate an unsteady flow of a viscous incompressible flow past an infinite isothermal vertical oscillating plate, in the presence of thermal radiation and chemical reaction. The fluid considered here is a gray, absorbing-emitting radiation but a nonscattering medium. The plate temperature is arised to $T_{w}$, and the concentration level near the plate is raised linearly with respect to time. An exact solution to the dimensionless governing equations has been obtained by the finite element method, when the plate is oscillating harmonically in its own plane. The effects of velocity, temperature, and concentration are studied for different physical parameters like thermal Grashof number, mass Grashof number, radiation parameter, prandtl number, chemical reaction parameter, Schmidt number, phase angle, and time are studied graphically. The skin-friction coefficient, the Nusselt number, and the Sherwood number at the plate are discussed, and their numerical values for various values of physical parameters are presented through tables.
\end{abstract}

\section{Introduction}

The present trend in the field of chemical reaction analysis is to give a mathematical model for the system to predict the reactor performance. The effect of a chemical reaction depends on whether the reaction is heterogeneous or homogeneous. This depends on whether they occur at an interface or as a single-phase volume reaction. In most cases of chemical reactions, the reaction rate depends on the concentration of the species itself. A reaction is said to be of the order $n$, if the reaction rate is proportional to the $n$th power of the concentration. In particular, a reaction is of first order, if the rate of reaction is directly proportional to concentration itself. Thermal radiation effects on heat and mass transfer play an important role in manufacturing industries for the design of fins, steel rolling, nuclear power plants, gas turbines, and various 
propulsion devices for air craft, missiles, satellites, and space vehicles are examples of such engineering applications. If the temperature of the surrounding fluid is rather high, radiation effects play an important role, and this situation does exist in space technology. England et al. [1] have studied the thermal radiation effects of a optically thin gray gas bounded by a stationary vertical plate. Radiation effect on mixed convection along a isothermal vertical plate was studied by Hossain and Takhar [2]. Raptis and Perdikis [3] studied the effects of thermal radiation and free convection flow past a moving vertical plate. The governing equations were solved analytically. Das et al. [4] have analyzed radiation effects on flow past an impulsively started infinite isothermal vertical plate.

The effect of a chemical reaction depends on whether the reaction is homogeneous or heterogeneous. This depends on whether they occur at an interface or as a single-phase volume reaction. In well-mixed systems, the reaction is heterogeneous, if it takes place at an interface and homogeneous, if it takes place in solution. Chambré and Young [5] have analyzed a first-order chemical reaction in the neighborhood of a stationary horizontal plate. Das et al. [6] have studied the effect of homogeneous first-order chemical reaction on the flow past an impulsively started infinite vertical plate with uniform heat flux and mass transfer. Again, mass transfer effects on moving isothermal vertical plate in the presence of chemical reaction studied by Das et al. [7]. The dimensionless governing equations were solved by the usual Laplace-trans form technique, and the solutions are valid only at lower time level.

The flow of a viscous, incompressible fluid past an infinite isothermal vertical plate, oscillating in its own plane, was solved by Soundalgekar (2.1). The effect on the flow past a vertical oscillating plate due to a combination of concentration and temperature differences was studied extensively by Soundalgekar and Akolkar [8]. Radiation effects on the oscillatory flow past vertical in the presence of uniform temperature analyzed by Mansour [9]. The governing were solved by perturbation technique. The effect of mass transfer on the flow past an infinite vertical oscillating plate in the presence of constant heat flux has been studied by Soundalgekar et al. [10]. Muthucumaraswamy [11] studied thermal radiation effects on vertical oscillating plate in the presence of variable temperature and mass diffusion. Mazumdar and Deka [12] considered the MHD flow past an impulsively started inifinite vertical plate in presence of thermal radiation. MHD and radiation with variable mass diffusion were considered by Muthucumaraswamy and Janakiraman [13]. Radiation and chemical reaction effects on isothermal vertical oscillating plate with variable mass diffusion have been studied by Manivannan et al. [14]. It is proposed to study chemical reaction and thermal radiation effects on unsteady flow past infinite isothermal vertical oscillating plate with variable mass diffusion. The dimensionless governing equations are solved using the finite element method. The effects of various governing parameters on the velocity, temperature, concentration, skin-friction coefficient, Nusselt number, and Sherwood number are shown in figures and tables and discussed in detail.

\section{Formulation of the Problem (Figure 1)}

Chemical reaction and thermal radiation effects on unsteady flow of a viscous incompressible fluid past an infinite isothermal vertical oscillating plate with variable mass diffusion are studied. Here we discussed the unsteady flow of a viscous incompressible fluid which is initially at rest and surrounds an infinite vertical plate with temperature $T_{\infty}$ and concentration $C_{\infty}^{\prime}$. Here, the $x^{\prime}$-axis is taken along the plate in the vertically up ward direction and the $y^{\prime}$ axis is taken normally to the plate. Initially, it is assumed that the plate and the fluid are of 


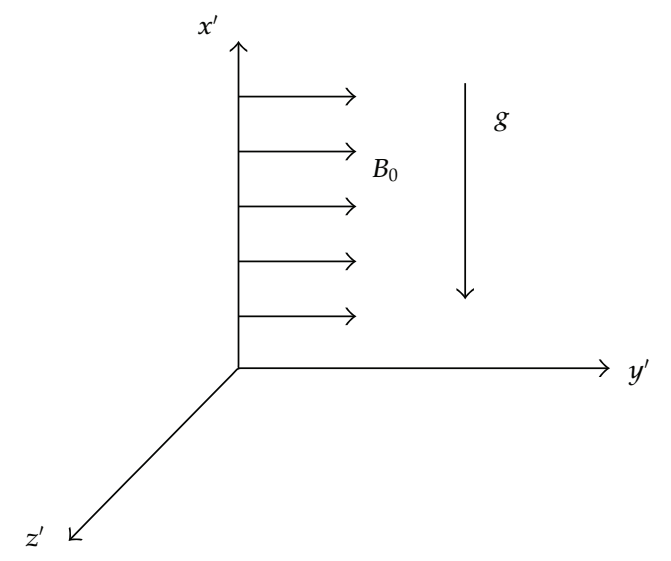

Figure 1: The physical model of the problem and coordinate system.

the same temperature and concentration. At time $t^{\prime}>0$, the plate starts oscillating in its own plane with frequency $w^{\prime}$ and the temperature of the plate is raised to $T_{w}$, and the concentration level near the plate is raised linearly with respect to time. The fluid considered here is a gray, absorbing-emitting radiation but a nonscattering medium. It is also assumed that there exists a homogeneous first-order chemical reaction between the fluid and species concentration. Then by usual Boussinesq's approximation, the unsteady flow is governed by the following equations:

$$
\begin{gathered}
\frac{\partial u^{\prime}}{\partial t^{\prime}}=v \frac{\partial^{2} u^{\prime}}{\partial y^{\prime 2}}+g \beta\left(T-T_{\infty}\right)+g \beta^{*}\left(C^{\prime}-C_{\infty}^{\prime}\right) \\
\rho C_{p} \frac{\partial T}{\partial t^{\prime}}=k \frac{\partial^{2} T}{\partial y^{\prime 2}}-\frac{\partial q_{r}}{\partial y} \\
\frac{\partial C^{\prime}}{\partial t^{\prime}}=D \frac{\partial^{2} C^{\prime}}{\partial y^{\prime 2}}-K_{1} C^{\prime}
\end{gathered}
$$

The initial and boundary conditions are as follows:

$$
\begin{array}{ll}
t^{\prime} \leq 0: & u^{\prime}=0, \quad T=T_{\infty}, \quad C^{\prime}=C_{\infty}^{\prime} \quad \forall y^{\prime}, \\
t^{\prime}>0: & u^{\prime}=u_{0} \cos w^{\prime} t^{\prime}, \quad T=T_{w}, \quad C^{\prime}=C_{w}^{\prime}+\left(C_{w}^{\prime}-C_{\infty}^{\prime}\right) A t^{\prime}, \quad \text { at } y^{\prime}=0, \\
& u^{\prime}=0, \quad T \longrightarrow T_{\infty}, \quad C^{\prime} \longrightarrow C_{\infty}^{\prime} \quad \text { as } y^{\prime} \longrightarrow \infty .
\end{array}
$$

The local radiant for the case of an optically thin gray gas is expressed by:

$$
\frac{\partial q_{r}}{\partial y}=-4 a^{*} \sigma\left(T_{\infty}^{4}-T^{4}\right)
$$


It is assumed they that the temperature differences within the flow are sufficiently small such that may be expressed as linear function of the temperature. This is accomplished by expanding in a Taylor series about and neglecting higher-order terms, thus:

$$
T^{4} \cong 4 T_{\infty}^{3} T-3 T_{\infty}^{4}
$$

By using (2.5) and (2.6), (2.2) reduces to

$$
\rho C_{p} \frac{\partial T}{\partial t^{\prime}}=k \frac{\partial^{2} T}{\partial y^{\prime 2}}+16 a^{*} \sigma T_{\infty}^{3}\left(T_{\infty}-T\right)
$$

The dimensional quantities are defined as

$$
\begin{gathered}
u=\frac{u^{\prime}}{u_{0}}, \quad y=\frac{u_{0} y^{\prime}}{v}, \quad t=\frac{u_{0}^{2} t^{\prime}}{v}, \quad K=\frac{u_{0}^{2} k^{\prime}}{v^{2}}, \quad \theta=\frac{T-T_{\infty}}{T_{w}-T_{\infty}}, \quad C=\frac{C^{\prime}-C_{\infty}^{\prime}}{C_{w}^{\prime}-C_{\infty}^{\prime}}, \\
\operatorname{Pr}=\frac{\mu C_{p}}{k}, \quad \mathrm{Sc}=\frac{v}{D}, \quad \mathrm{Gr}=\frac{g \beta v\left(T_{w}-T_{\infty}\right)}{u_{0}^{3}}, \quad \mathrm{Gm}=\frac{g \beta^{*} v\left(C_{w}^{\prime}-C_{\infty}^{\prime}\right)}{u_{0}^{3}}, \\
K=\frac{v K_{1}}{u_{0}^{2}}, \quad M=\frac{\sigma B_{0}^{2} v}{\rho u_{0}^{3}}, \quad w=\frac{w^{\prime} v}{u_{0}^{2}}, \quad A=\frac{u_{0}^{2}}{v} .
\end{gathered}
$$

In view of the (2.1), (2.2), and (2.3) reduce to the following dimensionless form:

$$
\begin{gathered}
\frac{\partial u}{\partial t}=\frac{\partial^{2} u}{\partial y^{2}}+\operatorname{Gr} \theta+\mathrm{GcC}, \\
\frac{\partial \theta}{\partial t}=\frac{1}{\operatorname{Pr}} \frac{\partial^{2} \theta}{\partial y^{2}}-\frac{R}{\operatorname{Pr}} \theta \\
\frac{\partial C}{\partial t}=\frac{1}{\mathrm{Sc}} \frac{\partial^{2} C}{\partial y^{2}}-K C
\end{gathered}
$$

where Gr, Gm, Pr, R, Sc, and $K$ are the thermal Grashof number, mass Grashof number, Prandtl number, radiation parameter, Schmidt number, and chemical reaction parameter, respectively.

The initial and boundary conditions in nondimensional form are

$$
\begin{array}{ll}
t \leq 0: & u=0, \quad \theta=0, \quad C=0, \quad \forall y, \\
t>0: & u=\cos w t, \quad \theta=1, C=t, \quad \text { at } y=0, \\
& u=0, \quad \theta \longrightarrow 0, \quad C \longrightarrow 0, \quad \text { as } y \longrightarrow \infty .
\end{array}
$$




\section{Solution of the Problem}

The linear functional for (2.9) over a typical line segment element $(e),\left(y_{j} \leq y \leq y_{k}\right)$ is

$$
J^{(e)}(u)=\frac{1}{2} \int_{y_{j}}^{y_{k}}\left\{\left(\frac{\partial u^{(e)}}{\partial y}\right)^{2}+2 u^{(e)} \frac{\partial u^{(e)}}{\partial t}-2 u^{(e)}(\mathrm{Gr} \theta+\mathrm{GmC})\right\} d y=\text { minimum. }
$$

Let $u^{(e)}=N_{j} u_{j}+N_{k} u_{k}$ be the linear piecewise approximation solution over the element $(e)$, $\left(y_{j} \leq y \leq y_{k}\right)$, where $u_{j}, u_{k}$ are the values of the function $u$ at the ends of the element $(e)$ and $N_{j}=y_{k}-y / y_{k}-y_{j}, \quad N_{k}=y-y_{j} / y_{k}-y_{j}$ are the basis functions. One obtains

$$
\frac{1}{l^{(e)}}\left[\begin{array}{cc}
1 & -1 \\
-1 & 1
\end{array}\right]\left[\begin{array}{l}
u_{j} \\
u_{k}
\end{array}\right]+\frac{l^{(e)}}{6}\left[\begin{array}{ll}
2 & 1 \\
1 & 2
\end{array}\right]\left[\begin{array}{l}
u_{j}^{\bullet} \\
u_{k}^{\bullet}
\end{array}\right]-(\mathrm{Gr} \theta+\mathrm{GmC}) \frac{l^{(e)}}{2}\left[\begin{array}{l}
1 \\
1
\end{array}\right]=0
$$

where dot denotes the differentiation with respect tot and $l^{(e)}=y_{k}-y_{j}$. Assembling the element equations for two consecutive elements $y_{i-1} \leq y \leq y_{i}$ and $y_{i} \leq y \leq y_{i+1}$, the following is obtained:

$$
\frac{1}{l^{(e)}}\left[\begin{array}{ccc}
1 & -1 & 0 \\
-1 & 2 & -1 \\
0 & -1 & 1
\end{array}\right]\left[\begin{array}{c}
u_{i-1} \\
u_{i} \\
u_{i+1}
\end{array}\right]+\frac{l^{(e)}}{6}\left[\begin{array}{lll}
2 & 1 & 0 \\
1 & 4 & 1 \\
0 & 1 & 2
\end{array}\right]\left[\begin{array}{c}
u_{i-1}^{\bullet} \\
u_{i}^{\bullet} \\
u_{i+1}^{\bullet}
\end{array}\right]=(\operatorname{Gr} \theta+\mathrm{GmC}) \frac{l^{(e)}}{2}\left[\begin{array}{l}
1 \\
2 \\
1
\end{array}\right]
$$

Now put row corresponding to the node $i$ to zero, the difference schemes with $l^{(e)}=h$ is

$$
\left(u_{i-1}^{\bullet}+4 u_{i}^{\bullet}+u_{i+1}^{\bullet}\right)=\frac{6}{h^{2}}\left(u_{i-1}+u_{i+1}\right)+\frac{12}{h^{2}} u_{i}+6(\mathrm{Gr} \theta+\mathrm{GmC})
$$

Applying the trapezoidal rule, the following system of equations in Crank-Nicholson method are obtained:

$$
\begin{aligned}
& (1-3 r) u_{i-1}^{j+1}+(4+6 r) u_{i}^{j+1}+(1-3 r) u_{i+1}^{j+1} \\
& \quad=(1+3 r) u_{i-1}^{j}+(4-6 r) u_{i}^{j}+(1+3 r) u_{i+1}^{j}+6 k\left(\mathrm{Gr} \theta_{i}^{j}+\mathrm{GmC}_{i}^{j}\right) .
\end{aligned}
$$

Now from (2.9), (2.10), and (2.11), following equations are obtained:

$$
\begin{aligned}
& (\operatorname{Pr}-3 r) \theta_{i-1}^{j+1}+(4 \mathrm{Pr}+6 r) \theta_{i}^{j+1}+(\mathrm{Pr}-3 r) \theta_{i+1}^{j+1} \\
& \quad=(\mathrm{Pr}+3 r) \theta_{i-1}^{j}+(4 \mathrm{Pr}-6 r) \theta_{i}^{j}+(\mathrm{Pr}+3 r) \theta_{i+1}^{j}+6 r R \\
& \left(2 \mathrm{Sc}+k_{r} \mathrm{Sc}-6 r\right) C_{i-1}^{j+1}+\left(4 \mathrm{Sc}+2 k_{r} \mathrm{Sc}+6 r\right) C_{i}^{j+1}+\left(2 \mathrm{Sc}+k_{r} \mathrm{Sc}-6 r\right) C_{i+1}^{j+1} \\
& \quad=\left(2 \mathrm{Sc}-k_{r} \mathrm{Sc}+6 r\right) C_{i-1}^{j}+\left(4 \mathrm{Sc}-2 k_{r} \mathrm{Sc}-6 r\right) C_{i}^{j}+\left(2 \mathrm{Sc}-k_{r} \mathrm{Sc}+6 r\right) C_{i+1}^{j} .
\end{aligned}
$$


Here $r=k / h^{2}$ and $h, k$ are mesh sizes along $y$-direction and timet- direction, respectively. Index $i$ refers to the space and $j$ refers to the time. In the above equations (3.5)-(3.7) taking $i=1(1) \quad n$ and using initial and boundary conditions (2.12), the following tridiagonal system of equations are obtained:

$$
\begin{aligned}
& A u=B, \\
& D \theta=E, \\
& F C=G,
\end{aligned}
$$

where $A, D$, and $F$ are tri-diagonal matrices of order $-n$ and whose elements are given by

$$
\begin{gathered}
a_{i, i}=4+6 r, \quad d_{i, i}=4 \mathrm{Pr}+6 r, \quad f_{i, i}=4 \mathrm{Sc}+2 k_{r} \mathrm{Sc}+6 r, \quad i=1(1) n \\
a_{i-1, j}=a_{i, j-1}=1-3 r, \quad d_{i-1, j}=d_{i . j-1}=\operatorname{Pr}-3 r, \\
f_{i-1, j}=f_{i, j-1}=2 \mathrm{Sc}+k_{r} \mathrm{Sc}-6 r, \quad i=2(1) n .
\end{gathered}
$$

Here $u, \theta, C$ and $B, E, G$ are column matrices having the $n$-components $u_{i}^{j+1}, \theta_{i}^{j+1}, C_{i}^{j+1}$ and $u_{i}^{j}, \theta_{i}^{j}, C_{i}^{j}$, respectively. The solutions of the above system of equations are obtained by using Thomas algorithm for velocity, temperature and concentration. Also, the numerical solutions for these equations are obtained by $C$-program. In order to prove the convergence and stability of Ritz finite element method, the computations are carried out for slightly changed values of $h$ and $k$ by running the same $C$-program. No significant change was observed in the values of $u, \theta$, and $C$. Hence, finite element method is convergent and stable.

The skinfriction, Nusselt number, and Sherwood number are important physical parameters for this type of boundary layer flow.

The skinfriction at the plate, which in the nondimensional form is given by

$$
C_{f}=\left(\frac{\partial u}{\partial y}\right)_{y=0}
$$

The rate of heat transfer coefficient, which in the nondimensional form in terms of the Nusselt number is given by

$$
\mathrm{Nu}=-\left(\frac{\partial \theta}{\partial y}\right)_{y=0} .
$$

The rate of mass transfer coefficient, which in the nondimensional form in terms of the Sherwood number, is given by

$$
\mathrm{Sh}=-\left(\frac{\partial C}{\partial y}\right)_{y=0} .
$$




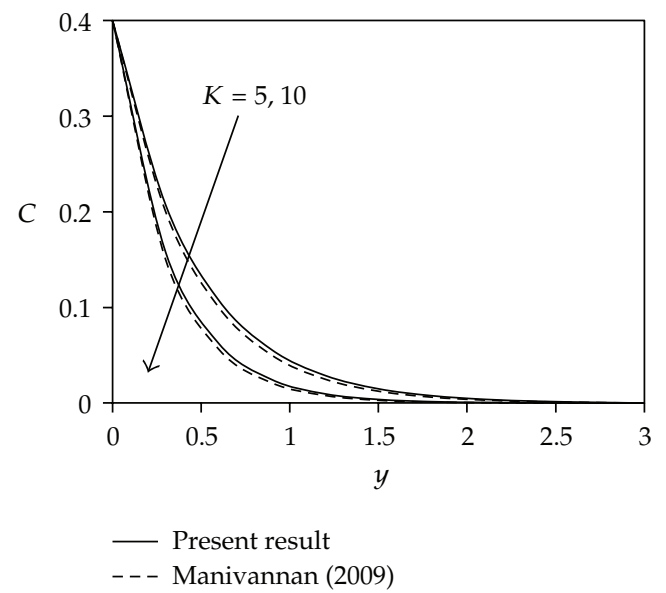

Figure 2: Comparison of concentration profiles at different values of $K$.

\section{Results and Discussion}

In order to get a physical insight of the problem numerical calculations are carried out for different physical parameters, namely, thermal Grashof number, mass Grashof number, Prandtl number, radiation parameter, chemical reaction Schmidt number, phase angle and time on the physical flow field, computations are carried out for velocity, temperature, and concentration and they are presented in figures below. In the present study we adopted the following default parameter values of finite element computations: $\mathrm{Gr}=2.0, \mathrm{Gm}=2.0, \mathrm{Pr}=$ $0.71, R=5.0, \mathrm{Sc}=0.6, K=2.0, w t=\pi / 4, t=0.4$. All graphs therefore correspond to these values unless specifically indicated on the appropriate figures.

In order to assess the accuracy of the numerical results, the present results are compared with the previous results. The velocity and concentration profiles for $t=0.4, w t=$ $\pi / 4, \mathrm{Gr}=2.0, \mathrm{Gc}=2.0, \operatorname{Pr}=0.71, R=5.0, \mathrm{Sc}=0.6$ are compared with the available solution of Manivannan [14] in Figure 2. It is observed that the present results are in good agreement with that of Manivannan [14].

The influence of thermal Grashof number Gr on the velocity is shown in Figure 3. The thermal Grashof number signifies the relative effect of the thermal buoyancy force to the viscous hydrodynamic force. The flow is accelerated due to the enhancement in buoyancy force corresponding to an increase in the thermal Grashof number, that is, free convection effects. The positive values of $\mathrm{Gr}$ correspond to cooling of the plate by natural convection. Heat is therefore conducted away from the vertical plate into the fluid which increases the temperature and thereby enhances the buoyancy force. In addition, it is seen that the peak values of the velocity increases rapidly near the plate as thermal Grashof number increase and then decays smoothly to the free stream velocity.

Figure 4 presents typical velocity profiles in the boundary layer for various values of the mass Grashof number Gc. The mass Grashof number Gc defines the ratio of the species buoyancy force to the viscous hydrodynamic force. It is noticed that the velocity increases with increasing values of the mass Grashof number.

Figures 5 and 6 illustrate the velocity and temperature profiles for different values of Prandtl number Pr. The numerical results show that the effect of increasing values of Prandtl number results in a decreasing velocity. It is observed that an increase in the Prandtl number 


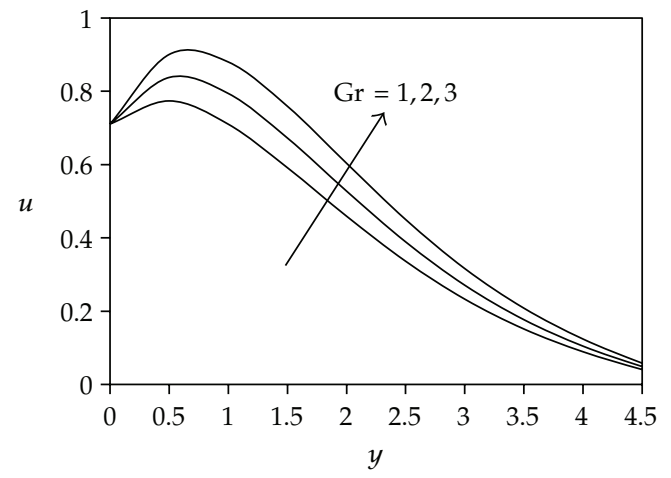

Figure 3: Velocity profile for different values of Gr.

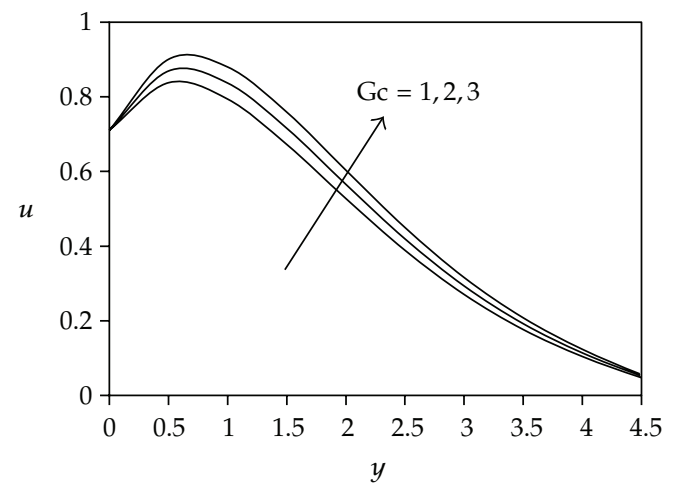

Figure 4: Velocity profile for different values of Gr values of Gc.

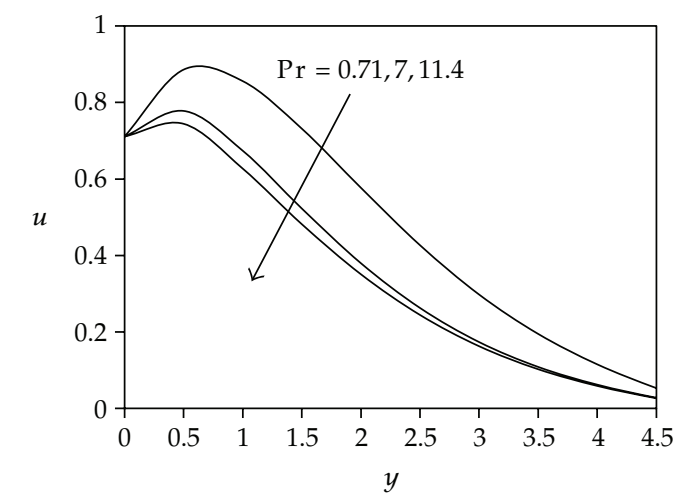

Figure 5: Velocity profile for different values of Pr.

results in a decrease of the thermal boundary layer thickness and in general lower average temperature with in the boundary layer. The reason is that smaller values of $\operatorname{Pr}$ are equivalent to increasing the thermal conductivities, and therefore heat is able to diffuse away from the heated surface more rapidly than for higher values of Pr. Hence in the case of smaller Prandtl numbers as the boundary layer is thicker and the rate of heat transfer is reduced. 


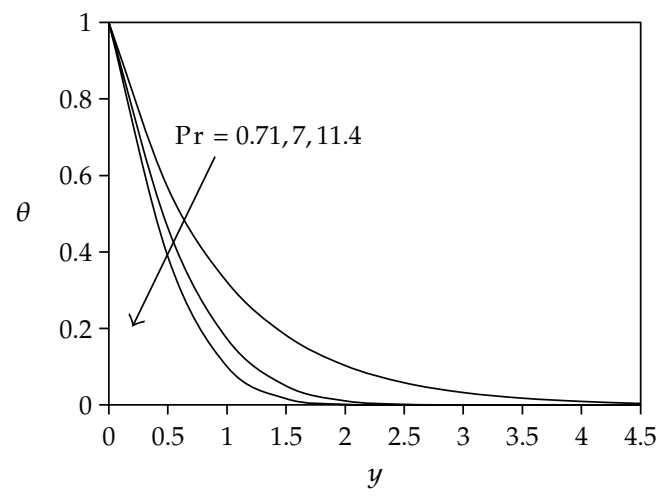

Figure 6: Temperature profile for different values of Pr.

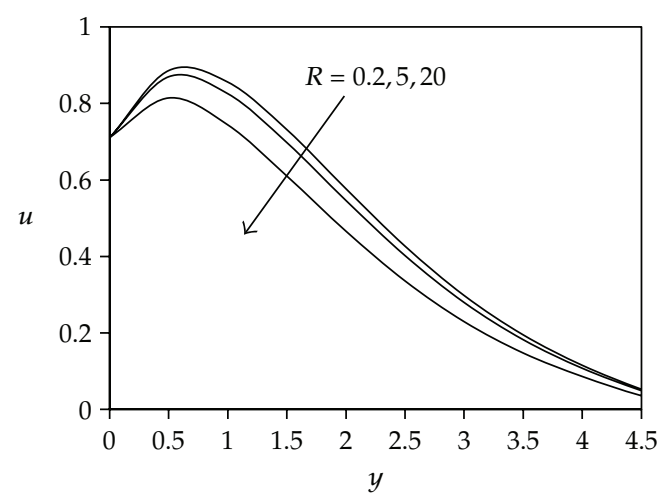

Figure 7: Velocity profile for different values of $R$.

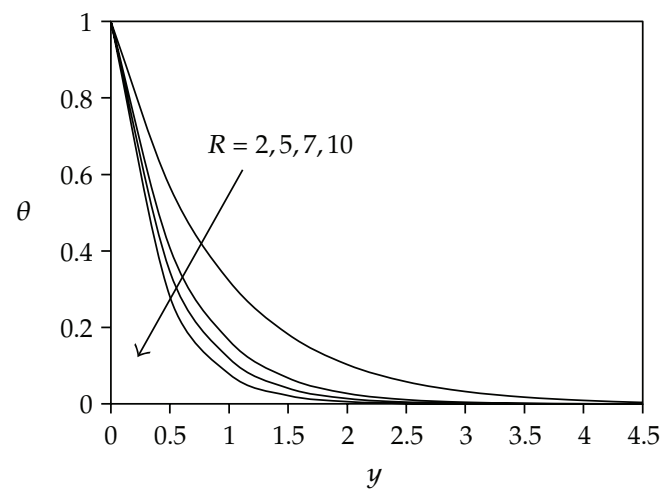

Figure 8: Temperature profile for different values of $R$.

For different values of the radiation parameter $R$, the velocity and the temperature profiles are shown in Figures 7 and 8. It is noticed that an increase in the radiation parameter results in a decrease in the velocity and temperature within the boundary layer, as well as decreased the thickness of the velocity and temperature boundary layers. 


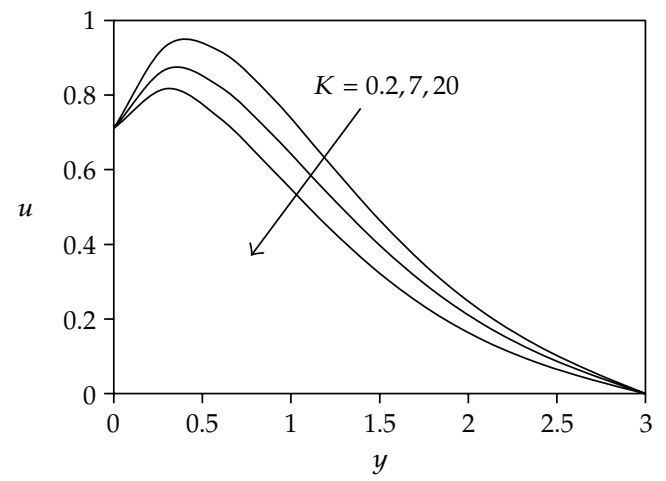

Figure 9: Velocity profile for different values of $K$.

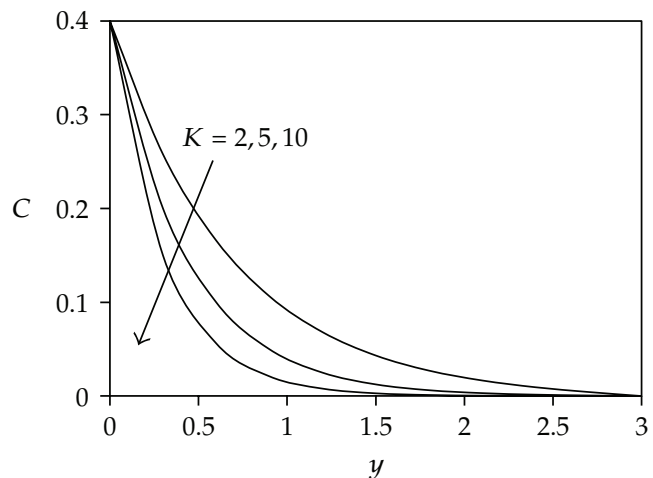

Figure 10: Concentration profile for different values of $K$.

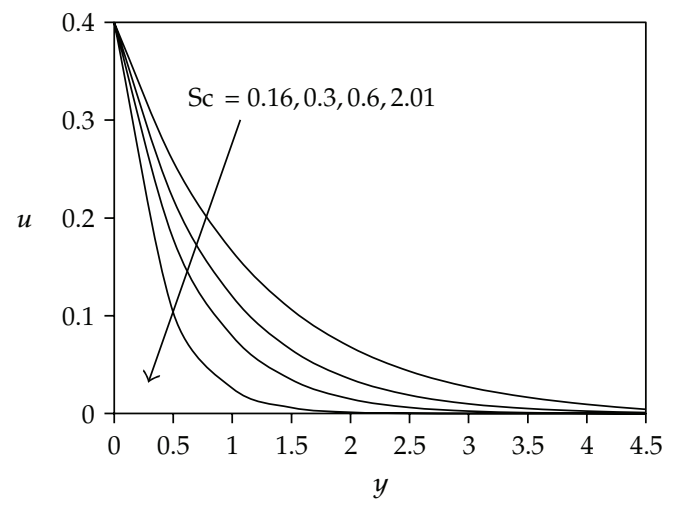

Figure 11: Velocity profile for different values of Sc.

Figure 9 represents the velocity profiles for different values of the chemical reaction parameter. The trend shows that the velocity increases with decreasing chemical reaction parameter. Figure 10 demonstrates the effect of the concentration profiles for different values of the chemical reaction parameter. It is observed that the concentration increases with decreasing chemical reaction parameter. 


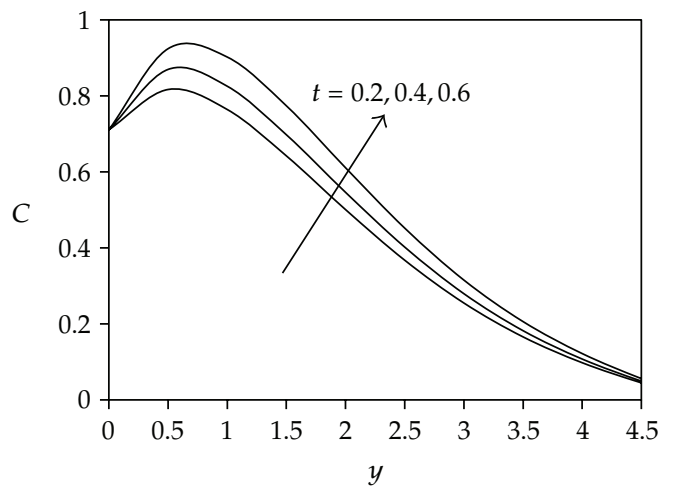

Figure 12: Concentration profile for different values of $t$.

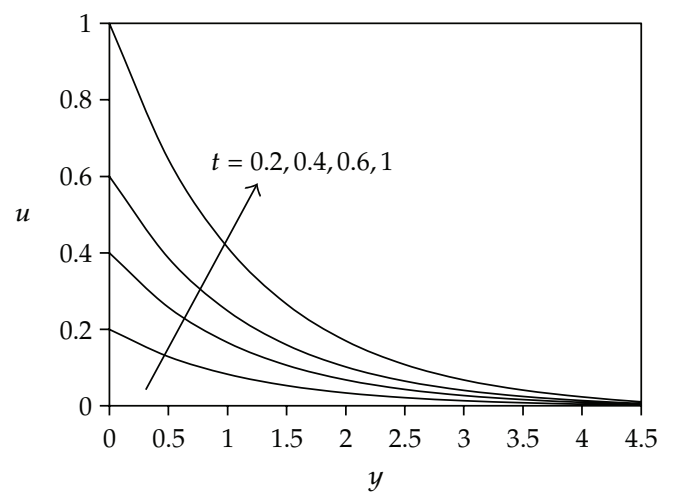

Figure 13: Velocity profile for different values of $t$.

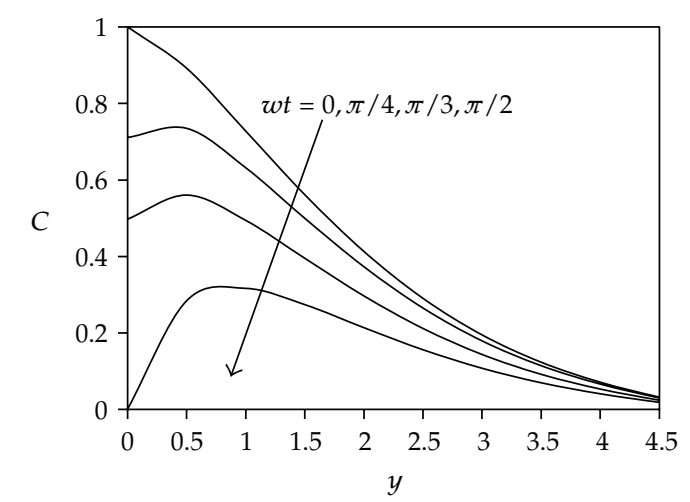

Figure 14: Concentration profile for different values of $w t$

Figure 11 represents the effect of concentration profiles for different Schmidt number. The effect of concentration is important in concentration field. The profiles have the common feature that the concentration decreases in a monotone fashion from the surface to a zero value far away in the free stream. It is observed that the wall concentration increases with decreasing values of the Schmidt number 
Table 1: Effect of $\mathrm{Gr}$ and $\mathrm{Gc}$ on $C_{f}(\operatorname{Pr}=7.0, R=2.0, \mathrm{Sc}=0.6, K=2.0, w t=\pi / 4, t=0.4)$.

\begin{tabular}{lrr}
\hline Gr & Gm & $C_{f}$ \\
\hline 1.0 & 1.0 & 1.2134 \\
2.0 & 1.0 & 1.8569 \\
1.0 & 2.0 & 1.7935 \\
\hline
\end{tabular}

Table 2: Effect of $\operatorname{Pr}$ and $R$ on $C_{f}$ and $\mathrm{Nu}(\mathrm{Gr}=2.0, \mathrm{Gm}=2.0, \mathrm{Sc}=0.6, K=2.0, w t=\pi / 4, t=0.4)$.

\begin{tabular}{lccc}
\hline $\operatorname{Pr}$ & $R$ & $C_{f}$ & $\mathrm{Nu}$ \\
\hline 0.71 & 2.0 & 1.2134 & 0.4152 \\
7.0 & 2.0 & 0.9472 & 0.4018 \\
0.71 & 5.0 & 1.1349 & 0.3056 \\
\hline
\end{tabular}

Table 3: Effect of $\mathrm{Sc}$ and $K$ on $C_{f}$ and $\mathrm{Sh}(\mathrm{Gr}=2.0, \mathrm{Gm}=2.0, \operatorname{Pr}=0.71, R=2.0, w t=\pi / 4, t=0.4)$.

\begin{tabular}{lccc}
\hline Sc & $K$ & $C_{f}$ & Sh \\
\hline 0.22 & 2.0 & 1.4253 & 0.2492 \\
0.60 & 2.0 & 1.2134 & 0.2326 \\
0.22 & 4.0 & 1.3468 & 0.2147 \\
\hline
\end{tabular}

The concentration profiles for different time are shown in Figure 12. The trend shows that the wall concentration increases with increasing values of the time $t$. The effects of velocity profiles for different time are shown in Figure 13. In this case, the velocity increases gradually with respect to time $t$. The velocity profiles for different phase angles are shown in Figure 14. It is observed that the velocity increases with decreasing phase angle $w t$.

The effects of $\mathrm{Gr}, \mathrm{Gm}, \mathrm{Pr}, R, \mathrm{Sc}$, and $K$ on the skin-friction $C_{f}$, Nusselt number $\mathrm{Nu}$, Sherwood number Sh are shown in Tables 1 to 3. From Table 1, it is observed that as Gr or $\mathrm{Gm}$ increases, the skin-friction coefficient increases. From Table 2, it is noticed that as $R$ increases, the skin-friction coefficient decreases, while the Nusselt number decreases and Pr increases, the skin-friction coefficient decreases, while the Nusselt number decreases. From Table 3, it is found that as Sc or $K$ increases, the skin-friction coefficient decreases while the Sherwood number decreases.

\section{Conclusions}

An exact analysis is performed to study thermal radiation effects on un steady flow past an infinite isothermal vertical oscillating plate, in the presence of variable wall concentration. The governing equations are solved using finite element method. The conclusions of the study are as follow.

(1) The velocity increases with decreasing phase angle $w t$ and radiation parameter $R$, the wall concentration increases with decreasing Schmidt number.

(2) The velocity as well as concentration decreases with an increase in the chemical reaction parameter.

(3) The temperature decreases due to high thermal radiation, and the leading edge effect is not affected by the oscillation of the plate. 
(4) Chemical reaction increases, the skin-friction coefficient decreases, while the Sherwood number decreases.

(5) Radiation parameter increases, the skin-friction coefficient decreases, while the Nusselt number decreases.

\section{Nomenclature}

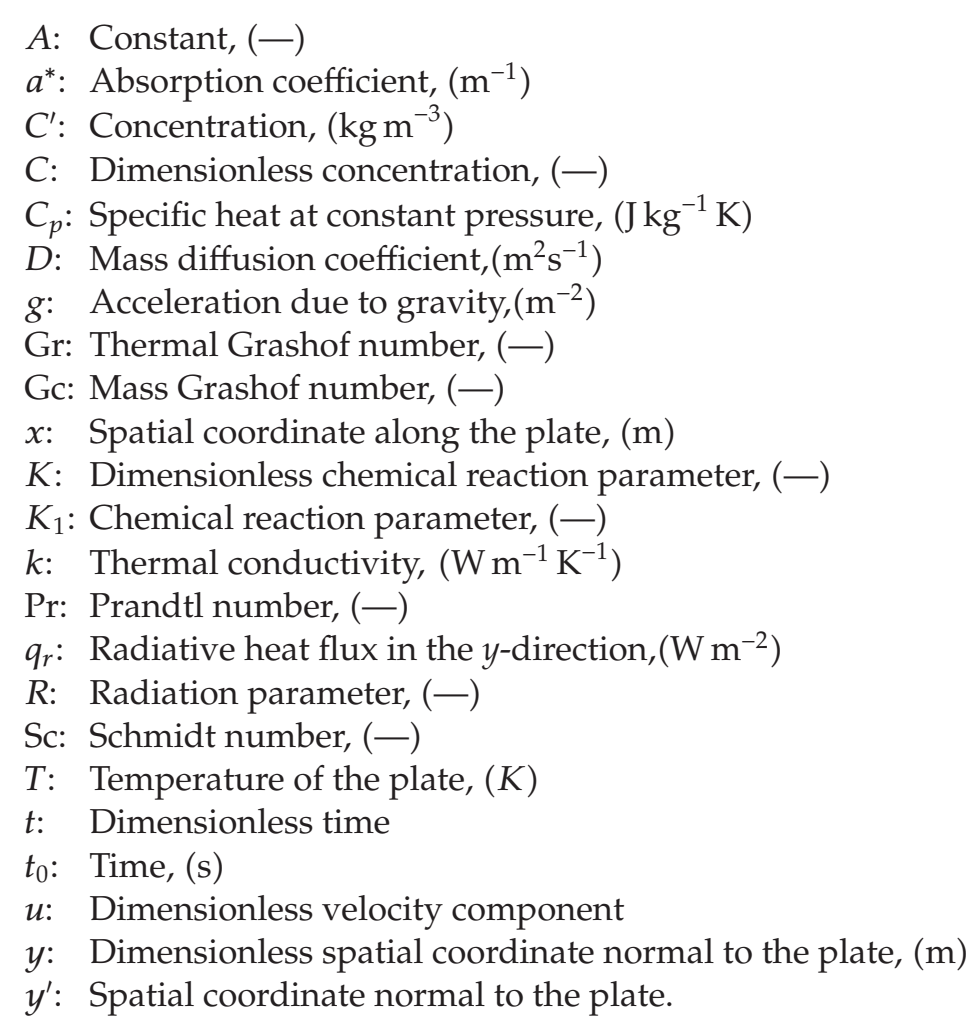

\section{Greek Symbols}

$\alpha$ : Thermal diffusivity, $\left(\mathrm{m}^{-2} \mathrm{~s}^{-1}\right)$

$\beta$ : Volumetric coefficient of thermal expansion, $\left(\mathrm{K}^{-1}\right)$ in the $x$ direction

$u^{\prime}$ : Velocity component in $x$-direction, $\left(\mathrm{m} \mathrm{s}^{-1}\right)$

$u_{0}$ : Amplitude of the oscillation, $\left(\mathrm{m} \mathrm{s}^{-1}\right)$

$\beta^{*}$ : Volumetric coefficient of expansion with concentration, $\left(\mathrm{K}^{-1}\right)$

$\mu$ : Coefficient of viscosity, (Ra.s)

$w t$ : Phase angle

v: Kinematic viscosity, $\left(\mathrm{m}+\mathrm{s}^{-1}\right)$

$\rho$ : Density of the fluid, $\left(\mathrm{kgm}^{-3}\right)$

$\tau$ : Dimensionless skinfriction, $\left(\mathrm{kgm}^{-1} \mathrm{~s}^{2}\right)$

$\sigma$ : Stefan-Boltzman constant, $\left(\mathrm{Wm}^{-2} \mathrm{~K}^{-4}\right)$

$\theta$ : Dimensionless temperature

$\eta$ : Similarity parameter. 


\section{Subscripts}

$\omega:$ Conditions on the wall

$\infty$ : Free stream conditions.

\section{References}

[1] W. G. England and A. F. Emery, "Thermal radiation effects on the laminar free convection boundary layer of an absorbing gas," Journal of Heat Transfer, vol. 91, no. 1, pp. 37-44, 1969.

[2] M. A. Hossain and H. S. Takhar, "Radiation effect on mixed convection along a vertical plate with uniform surface temperature," Heat and Mass Transfer, vol. 31, no. 4, pp. 243-248, 1996.

[3] A. Raptis and C. Perdikis, "Radiation and free convection flow past a moving plate," International Journal of Applied Mechanics and Engineering, vol. 4, no. 4, pp. 817-821, 1999.

[4] U. N. Das, R. K. Deka, and V. M. Soundalgekar, "Radiation effects on flow past an impulsively started vertical infinite plate," Journal of Theoretical Mechanics, vol. 1, no. 5, pp. 111-115, 1996.

[5] P. L. Chambré and J. D. Young, "On the diffusion of a chemically reactive species in a laminar boundary layer flow," Physics of Fluids, vol. 1, no. 1, pp. 48-54, 1958.

[6] U. N. Das, R. Deka, and V. M. Soundalgekar, "Effects of mass transfer on flow past an impulsively started infinite vertical plate with chemical reaction," The Bulletin, GUMA, vol. 5, no. 1, pp. 13-20, 1999.

[7] U. N. Das, R. Deka, and V. M. Soundalgekar, "Effects of mass transfer on flow past an impulsively started infinite vertical plate with constant heat flux and chemical reaction," Forschung im Ingenieurwesen, vol. 60, no. 10, pp. 284-287, 1994.

[8] V. M. Soundalgekar and S. P. Akolkar, "Effects of free convection currents and mass transfer on flow past a vertical oscillating plate," Astrophysics and Space Science, vol. 89, no. 2, pp. 241-254, 1983.

[9] M. A. Mansour, "Radiative and free-convection effects on the oscillatory flow past a vertical plate," Astrophysics and Space Science, vol. 166, no. 2, pp. 269-275, 1990.

[10] V. M. Soundalgekar, "Effects of mass transfer on the flow past an oscillating infi nite vertical plate with constant heat flux," Thermo Physics and Aero Mechanics, vol. 1, no. 3, pp. 119-124, 1994.

[11] R. Muthucumaraswamy, "The interaction of thermal radiation on vertical oscillating plate with variable temperature and mass diffusion," Theoretical and Applied Mechanics, vol. 33, no. 2, pp. 107-121, 2006.

[12] M. K. Mazumdar and R. K. Deka, "MHD flow past an impulsively started infinite vertical plate in presence of thermal radiation," Romanian Journal of Physics, vol. 52, pp. 529-535, 2007.

[13] R. Muthucumaraswamy and B. Janakiraman, "MHD and radiation effects on moving isothermal vertical plate with variable mass diffusion," Theoretical and Applied Mechanics, vol. 33, no. 1, pp. 17-29, 2006.

[14] K. Manivannan, R. Muthucumaraswamy, and V. Thangaraj, "Radiation and chemical reaction effects on isothermal vertical oscillating plate with variable mass diffusion," Thermal Science, vol. 13, no. 2, pp. 155-162, 2009. 


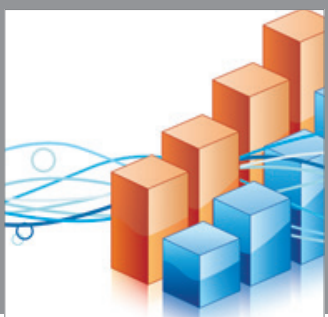

Advances in

Operations Research

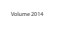

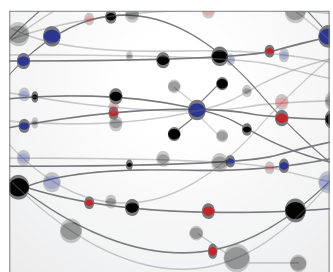

\section{The Scientific} World Journal
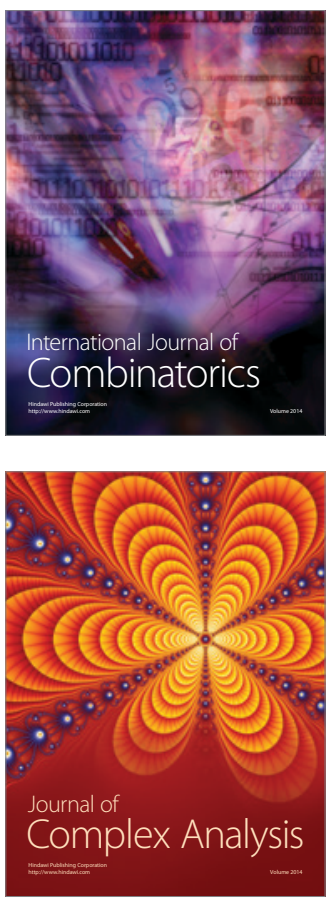

International Journal of

Mathematics and

Mathematical

Sciences
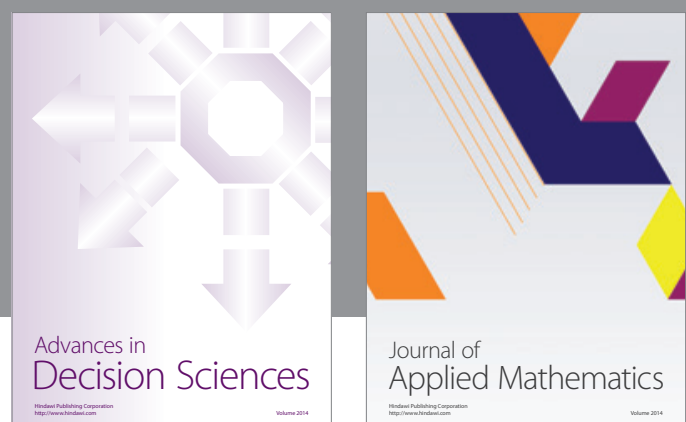

Journal of

Applied Mathematics
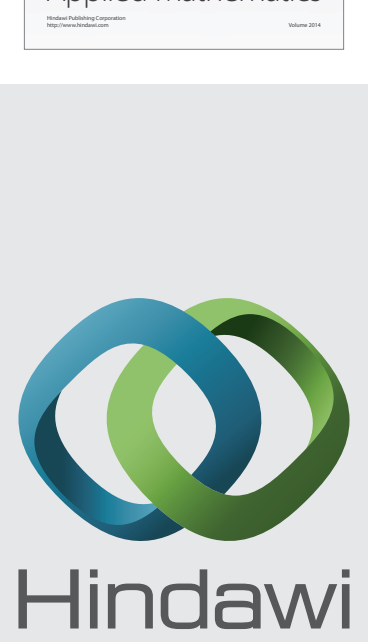

Submit your manuscripts at http://www.hindawi.com
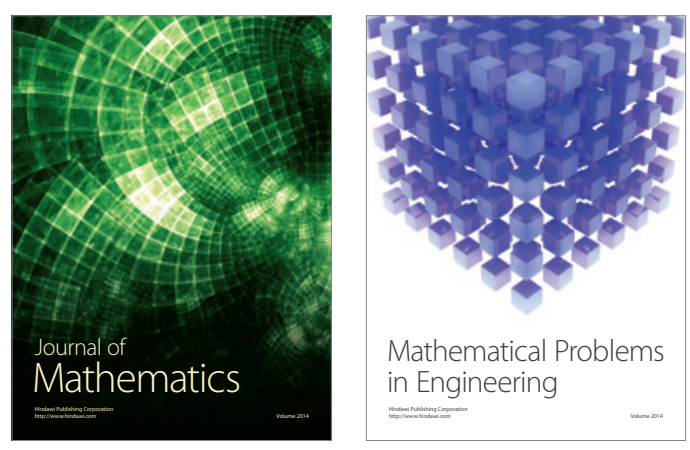

Mathematical Problems in Engineering
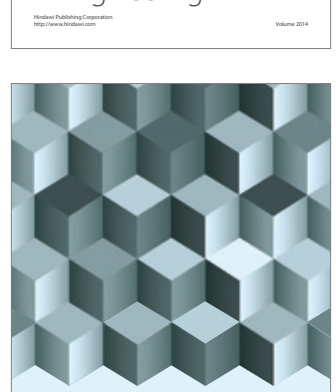

Journal of

Function Spaces
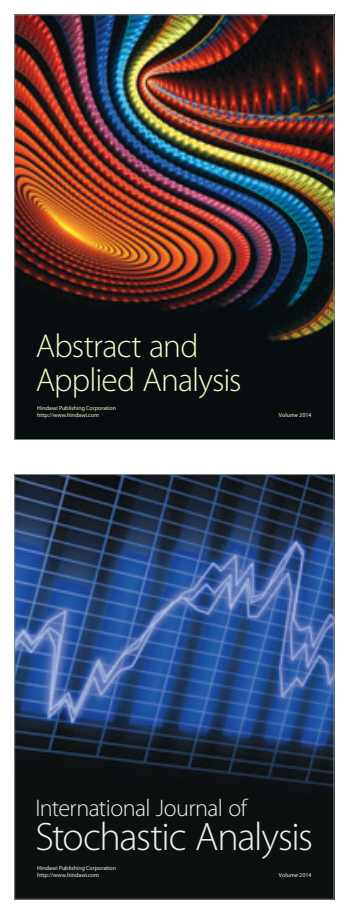

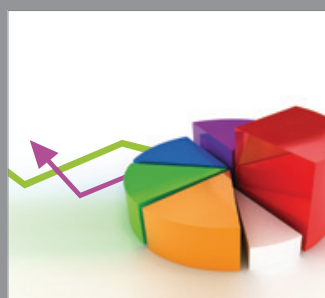

ournal of

Probability and Statistics

Promensencen
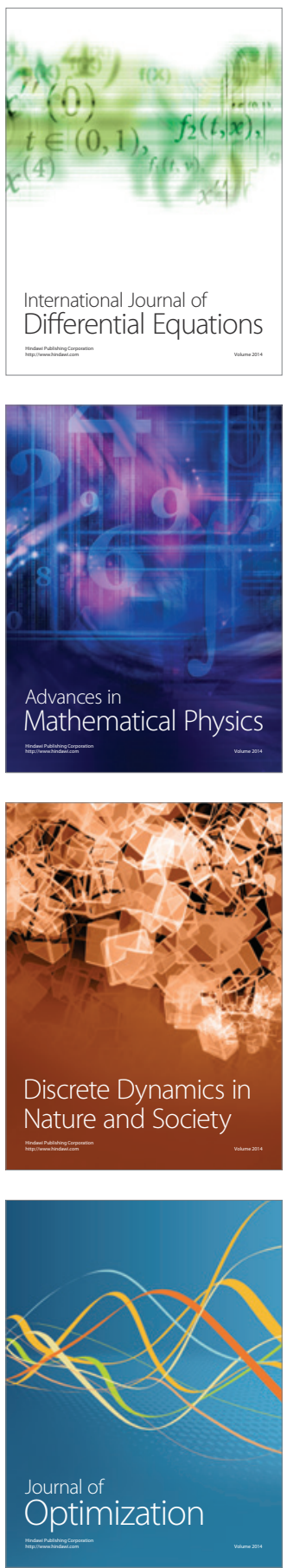